\title{
THE ROLE OF MEAN PLATELET VOLUME AS A BIOMARKER IN ACUTE EXACERBATION OF BRONCHIAL ASTHMA
}

\author{
By \\ El-Soudy Awad Mohammed Mustafa ${ }^{\text {a }}$, Ibrahim Hassan El-Bana \\ Ibrahim $^{\text {a }}$, Ahmed Ali Ali Assem ${ }^{\mathrm{a}}$ and Refaat Abo El-Fotoh Abo El-Saad \\ Department of Chest, Faculty of medicine, Al-Azhar University, Cairo, Egypt \\ Corresponding author: El-Soudy Awad Mohammed, \\ Mobile: 01004172549, E-mail: soudybadr2@yahoo.com
}

\begin{abstract}
Background: Airflow limitation in bronchial asthma is recurrent and produced by a variety of changes in the airway as bronchoconstriction, airway edema, hyper responsiveness, remodeling and cellular inflammation. Plasma $\beta$-thrombomodulin and platelet factor- 4 , common markers of platelet activation in vivo, have been reported to be elevated in symptomatic asthmatic patients' platelets express more P-selectin on their surface in asthmatic patients. The mean platelet volume, a common measure of platelet size, could be used as an indicator of activated platelets.
\end{abstract}

Objectives: To measure mean platelet volume in asthmatic patients to assess its use as a biomarker for asthma exacerbation.

Patients and Methods: This was a case control study involved 50 asthmatic patients during both stable and exacerbation, in addition to 50 age and sex matched healthy subjects as a control group. Measurements of platelet count, mean platelet volume (MPV), C reactive protein (CRP) and spiro metric indices were performed for all participants.

Results: Mean platelet volume (MPV) was significantly lower in exacerbation phase compared to both stable and control Group ( $\mathrm{p}<.01)$, while it non significantly decreased in stable phase compared to control group. During acute exacerbation, the MPV /fl was positively correlated with FEV1\%, FEV1/FVC ratio, VC\%, FVC\%, HB level, while it was negatively correlated with age, WBC, CRP, neutrophil percentage. Moreover, they were positively correlated with each other. During stable asthma phase, the MPV /fl was positively correlated with FEV1\%, FEV1/FVC ratio, VC\%, FVC\%, HB level, while it was negatively correlated with age, WBC, CRP, neutrophil percentage. Moreover, they were positively correlated with each other.

Conclusion: MPV was altered in exacerbation phase compared with stable phase and control group. Measurement of the MPV is a valuable indicator of asthma severity/activity and appears as a useful screening test for asthma exacerbation.

Key words: Asthma exacerbation, Mean platelet volume, Spirometric pulmonary function, asthma pathogenesis.

\section{INTRODUCTION}

Asthma is a heterogeneous disease, usually characterized by chronic airway inflammation. It is defined by a history of respiratory symptoms such as wheeze, shortness of breath, chest tightness and cough that vary over time and in intensity, together with variable expiratory airflow limitation. These variations are often triggered by factors such as exercise, allergen or irritant exposure, change in 


\section{EL-SOUDY A. MOHAMMED et al.,}

weather, or viral respiratory infections. Symptoms and airflow limitation may resolve spontaneously or in response to medication (Reddel and levy, 2015).

Exacerbations may occur in patients with a pre- existing diagnosis of asthma or, occasionally, as the first presentation of asthma. It usually occurs in response to exposure to an external agent (e.g., viral upper respiratory tract infection, pollen or pollution) and/or poor adherence with controller medication (Ullmann et al., 2018).

Studies have indicated that low levels of MPV are due to the consumption of activated or large platelets under highgrade inflammatory conditions and this is reversed during the course of antiinflammatory therapy (Yuri Gasparyan et al., 2011).

Reduction in the MPV value may be related to the migration of large young platelets to the site of inflammation and a relative decrease in the circulation. Inflammatory conditions lead to changes in the platelet membrane and internal structure. It has been reported that depolymerization occurs in the microtubular structure of the platelets and changes occur in the structure of actin polymerization during inflammation. As a result, platelets change their shapes and this change which are reflected in the MPV (Flad and Brandt et al., 2010).

CRP production is a part of the nonspecific acute-phase response to most forms of inflammation and infection, A positive relationship has been reported between raised CRP levels and asthma exacerbation (Alobaidi et al., 2010).
The present work aimed to: To measure mean platelet volume in asthmatic patients to assess its use as a biomarker for asthma exacerbation.

\section{PATIENTS AND METHODS}

This observation case - control study was conducted at Chest Diseases Department of Bab Elsharia hospital during the period from January 2019 to July 2019. It included 50 patients who were admitted with symptoms of asthma exacerbation.

\section{Inclusion criteria:}

Bronchial asthma patient group and 50 apparent healthy individuals without symptoms suggestive of any chest diseases. Their Spirometric indices and plain chest $\mathrm{X}$ ray were normal.

\section{Exclusion Criteria:}

Patients with malignancies, patients with the hematological disorder, patients with valvular diseases, patients with autoimmune diseases, patients with hepatic failure, patient with renal failure, patient with heart failure, patient treated with an anticoagulant, statins, angiotensin converting enzyme, acetylsalicylic acid, clopidogrel, patients with coronary artery disease and patients with acute severe asthma.

Asthma exacerbation was defined as the
existence of any one of the following
events: Emergency visits related to
asthmatic attack (asthmatic attack-related
hospitalization), or the use of systematic
corticosteroids for at least 3 days. Inhaled
short-acting and long-acting $\beta 2$-agonist,
inhaled steroids, oral steroids, and
antibiotics were ordered to treat asthma
exacerbation. After 6 weeks following the 
attack, the patients were re-evaluated when they were symptom free. Stable asthma was defined as no exacerbation of symptoms in the past 6 weeks.

Ethical Considerations: An informed Consent was obtained from each participant.

\section{Methodology:}

All participants were subjected to Spirometry, Complete blood count testing and High-sensitivity CRP assay.

Spirometry, $\mathrm{CBC}$ and CRP were repeated 6 weeks later after improvement.
Statistical analysis: Data were fed to the computer and analyzed using IBM SPSS Corp. Released 2013. IBM SPSS Statistics for Windows, Version 22.0. Armonk, NY: IBM Corp. Qualitative data were described using number and percent. Quantitative data were mean, standard deviation and range for parametric data after testing normality using KolmogorovSmirnov test. P-values $\leq 0.05$ were considered significant. Independent sample t-test was used in comparing the means of two groups, while spearman Correlation Coefficient test (r) was used to study the degrees of correlation.

\section{RESULTS}

This study included 100 subjects, 50 cases and 50 controls. No statistically Significant difference between control and cases regarding their demographic characteristics (age, sex and body mass index) with their mean age $36.24 \& 39.96$ years, respectively (Table 1).

Table (1): Comparison between bronchial asthma group and control group regarding age, sex and body mass index

\begin{tabular}{|c|c|c|c|}
\hline $\begin{array}{ll}\text { Parameters } & \text { Groups } \\
\end{array}$ & $\begin{array}{c}\text { Control group } \\
n=50\end{array}$ & $\begin{array}{c}\text { Bronchial asthma group } \\
\qquad \mathbf{n}=50\end{array}$ & $P$ value \\
\hline $\begin{array}{l}\text { Age (years) } \\
\text { Mean } \pm \text { SD }\end{array}$ & $36.24 \pm 8.97$ & $39.96 \pm 9.36$ & \multirow{2}{*}{$\mathrm{p}=0.045$} \\
\hline Range & $18-50$ & $18-59$ & \\
\hline $\begin{array}{l}\text { Sex } \\
\text { Males } \\
\text { Females }\end{array}$ & $\begin{array}{c}\mathrm{N}(\%) \\
20(40.0) \\
30(60.0)\end{array}$ & $\begin{array}{c}\mathrm{N}(\%) \\
27(54.0) \\
23(46.0)\end{array}$ & $\mathrm{P}=0.161$ \\
\hline $\begin{array}{l}\text { BMI }\left(\mathrm{Kg} / \mathbf{m}^{2}\right) \\
\text { Mean } \pm \text { SD }\end{array}$ & $29.39 \pm 6.39$ & $29.11 \pm 6.34$ & \multirow{2}{*}{$\mathrm{p}=0.826$} \\
\hline Range & $19.4-43.8$ & $20-43.0$ & \\
\hline
\end{tabular}

SD, Standard deviation; BMI, Body Mass Index; Kg, kilogram; m, meter

There were statistically significant lower mean spirometric pulmonary function tests among asthmatic cases during acute exacerbation than control group $(\mathrm{p}<0.05)$. Mean FEV1/FVC\%, FEV1\%, FVC predicted\%, VC predicted $\%$, and FEF $25-75$ predicted $\%$ were $70.35,57.82,82.14,8.16 \& 59.7$ versus $90.8,82.02,85.0,90.18 \& 73.96$ respectively for cases during acute exacerbation and control groups. Comparing cases during acute exacerbation and during stable phase; illustrate that there are statistically significant lower mean spirometric pulmonary function tests among asthmatic (Table 2). 
EL-SOUDY A. MOHAMMED et al.,

Table (2): Comparison of Spirometric pulmonary function test between studied groups

\begin{tabular}{|c|c|c|c|c|c|c|}
\hline \multirow[t]{2}{*}{ Groups } & \multicolumn{2}{|c|}{$\begin{array}{l}\text { Bronchial asthma group } \\
\qquad \mathbf{N}=\mathbf{5 0}\end{array}$} & \multirow{2}{*}{$\begin{array}{c}\text { Control } \\
n=50\end{array}$} & \multicolumn{3}{|c|}{ Post Hoc Tukey test } \\
\hline & $\begin{array}{c}\text { Exacerbation } \\
\text { phase }\end{array}$ & Stable phase & & $\mathrm{p} 1$ & $\mathrm{p} 2$ & p3 \\
\hline FEV/FVC \% & $70.35 \pm 3.51$ & $73.36 \pm 7.7$ & $90.8 \pm 7.9$ & $\mathrm{P}<0.001$ & $\mathrm{P}<0.001$ & $\mathrm{P}<0.001$ \\
\hline FEV1\% & $57.82 \pm 4.23$ & $63.26 \pm 5.48$ & $82.02 \pm 4.94$ & $\mathrm{P}<0.001$ & $\mathrm{P}<0.001$ & $\mathrm{P}<0.001$ \\
\hline FVC predicted $\%$ & $82.14 \pm 3.60$ & $86.50 \pm 4.40$ & $85.0 \pm 5.47$ & $\mathrm{P}<0.001$ & $\mathrm{P}<0.001$ & P0.04 \\
\hline VC predicted $\%$ & $86.16 \pm 4.52$ & $88.56 \pm 3.92$ & $90.18 \pm 7.39$ & $\mathrm{P}=0.04$ & $\mathrm{P}=0.001$ & $\mathrm{P}<0.001$ \\
\hline $\begin{array}{l}\text { FEF } 25-75 \\
\text { predicted } \%\end{array}$ & $59.70 \pm 3.39$ & $64.32 \pm 5.38$ & $73.96 \pm 5.36$ & $\mathrm{P}<0.001$ & $\mathrm{P}<0.001$ & $\mathrm{P}<0.001$ \\
\hline
\end{tabular}

All parameters were described as mean $\pm \mathrm{SD}, \mathrm{p} 1$ :difference between cases during acute exacerbation and during stable phase, p2: difference between cases during stable phase and control group, p3:difference between cases during stable phase and control group

Comparing between control and cases during acute exacerbation, there was a statistically significant higher mean WBCS, eosinophils, lymphocytes, RBCS and CRP among cases with acute exacerbation phase than control group. Lower mean HB and MPV among cases was detected during acute attack than control group with statistically significant difference between them. Similarly; comparing between cases during acute exacerbation and during stable phase shows statistically significant higher mean WBCS, esinophils, lymphocytes, RBCS and CRP among cases with acute exacerbation than stable phase. Lower mean HB and MPV among cases were detected among cases with acute exacerbation than stable phase with statistically significant differences between them. Comparison between control and cases during stable phase demonstrated statistically significant higher mean lymphocytes and CRP among cases with stable phase than control group. Lower mean MPV among cases was detected during stable phase than control group with statistically significant difference between them, and there was statistically significant difference between control group and cases after acute exacerbation regarding WBCS count, eosinophils, lymphocytes, hemoglobin and MPV, while median platelet count and median RBCS have no statistically significant difference between studied groups (Table 3). 
THE ROLE OF MEAN PLATELET VOLUME AS A BIOMARKER IN...

Table (3): Comparison of $\mathrm{CBC}$ results between studied groups

\begin{tabular}{|c|c|c|c|c|c|c|}
\hline Groups & \multicolumn{2}{|c|}{$\begin{array}{l}\text { Bronchial asthma group } \\
\qquad \mathrm{N}=\mathbf{5 0}\end{array}$} & \multirow{2}{*}{$\begin{array}{c}\text { Control } \\
n=50\end{array}$} & \multicolumn{3}{|c|}{ Post Hoc Tukey test } \\
\hline CBC & $\begin{array}{l}\text { Exacerbation } \\
\text { phase }\end{array}$ & Stable phase & & $\mathrm{p} 1$ & p2 & p3 \\
\hline $\mathrm{WBCS}\left(\mathbf{m} / \mathbf{m m}^{\mathbf{3}}\right)$ & $9.09 \pm 1.38$ & $7.93 \pm 1.63$ & $7.54 \pm 1.38$ & $<0.001$ & $<0.001$ & 0.209 \\
\hline Eosinophil (\%) & $1.162 \pm 0.91$ & $0.599 \pm 0.47$ & $0.611 \pm 0.45$ & $<0.001$ & $<0.001$ & 0.899 \\
\hline Platelet $\left(\mathrm{m} / \mathrm{mm}^{3}\right)$ & $362.82 \pm 40.09$ & $352.10 \pm 39.66$ & $356.96 \pm 43.95$ & 0.05 & 0.488 & 0.563 \\
\hline $\begin{array}{l}\text { Lymphocytes } \\
(\%)\end{array}$ & $55.11 \pm 14.22$ & $47.82 \pm 4.18$ & $40.90 \pm 9.29$ & $<0.001$ & $<0.001$ & $<0.001$ \\
\hline $\operatorname{RBC}\left(\mathbf{m} / \mathbf{m m}^{3}\right)$ & $5.16 \pm 1.58$ & $3.86 \pm 0.89$ & $4.0 \pm 0.87$ & $<0.001$ & $<0.001$ & 0.415 \\
\hline HGB ( g/dl) & $10.45 \pm 1.64$ & $11.66 \pm 1.42$ & $11.35 \pm 1.12$ & 0.003 & 0.002 & 0.254 \\
\hline MPV(fl) & $7.76 \pm 1.51$ & $9.46 \pm 1.42$ & $11.66 \pm 1.25$ & $<0.001$ & $<0.001$ & $<0.001$ \\
\hline CRP & $24.12 \pm 14.06$ & $16.92 \pm 6.26$ & $6.52 \pm 1.50$ & $<0.001$ & $<0.001$ & $<0.001$ \\
\hline
\end{tabular}

CBC, Complete Blood Count; MPV, Mean Platelet Volume; CRP, C Reactive Protein

All parameters were described as mean \pm SD, p1: difference between cases during acute exacerbation and during stable phase, p2: difference between cases

\section{DISCUSSION}

Mean platelet volume values reflect the platelet size. Platelet size is determined at the level of progenitor cell (i.e., the megakaryocyte). Some studies reported that cytokines such as interleukin 3 (IL-3) and interleukin 6 (IL-6) influence megakaryocyte ploidy and can lead to the production of more reactive larger platelets. IL-6 and IL-3 are the cytokines that are produced by Th2 cells (Tuncel et al., 2012).

No significant difference was detected between cases and controls regarding age. Moreover, no significant difference was also detected regarding gender. In accordance with our results, Nacaroglu et al. (2016) reported that no significant difference between cases and controls regarding age and gender.

In our study, FEV1 predicted significantly reduced in acute exacerbated cases compared to controls. Additionally, during acute exacerbation phase and control group, p3: difference between cases during stable phase and control group

it was significantly reduced in exacerbated cases compared to stable cases. These findings are consistent with that reported by Agapakis et al. (2016). As FEV1 predicted significantly decreased in disease group compared to controls. Besides, it was significantly higher in the acute exacerbated cases compared to stable ones.

In the current study, FEV1/FVC markedly decreased in exacerbated cases compared to controls. Additionally, it showed slightly decrease in exacerbated cases compared to stable ones. In a previous Egyptian study by Hafez et al. (2019), The FEV1/FVC significantly decreased in exacerbated cases compared to stable ones. Also, diseased individuals had significantly lower FEV1/FVC values compared to controls.

In our study, CRP elevated in exacerbated cases compared to stable and control cases. Agapakis et al. (2016) showed that CRP elevated significantly in 
cases compared to controls. Additionally, it was higher in cases with acute exacerbation compared to stable cases. Hafez et al. (2019) also stated that CRP significantly elevated in exacerbation phase compared to controls and stable cases. Moreover, stable cases had significantly higher levels compared to controls.

Regarding platelet count in our study, it did not differ significantly between controls and exacerbated cases. Likewise, exacerbated and stable cases did not have any significant difference regarding the same parameter. Tuncel et al. (2012) found that the number of platelets in asthmatic patients during and after the attack compared to healthy subjects had no significant difference.

Same variability in platelet count was found among asthmatic children, as Nacaroglu et al. (2016) reported that platelet count significantly increased in the patient group either in exacerbation phase or asymptomatic periods compared with controls. Dogru et al. (2015) reported that the platelet count was significantly higher in both stable asthmatic and exacerbated asthmatic patients compared with controls, whereas there was no significant difference between stable asthmatic and exacerbated asthmatic patients.

MPV in the current study was significantly lower in exacerbated cases compared to controls. Moreover, exacerbated cases had significantly lower values compared to stable ones. Sun et al. (2014) reported that MPV values were lower during periods of asthma exacerbation compared to asymptomatic periods. Tural Kara et al. (2015) showed that MPV decreased significantly during asthmatic attack compared to after attack. Moreover, the platelet crit value showed the same change. Nevertheless, platelet count did not differ significantly between cases during and after attack. Agapakis et al. (2016) reported that MPV was significantly decreased in cases with COPD compared to controls. Moreover, MPV decreased significantly in cases with acute exacerbation compared to stable cases. Dolap et al. (2018) have claimed that the levels of MPV values drop due to the consumption of active or large platelets in severe inflammatory conditions and that this can be reversed by anti-inflammatory treatments.

Our study further supported this theory that MPV can also be a marker for acute attacks in patients with asthma. These findings indicated that platelet indices are more sensitive biomarkers for asthma exacerbation than platelets count. Tuncel et al. (2012) demonstrated that MPV values in asthmatic children both during an asthmatic attack and during the asymptomatic period had no statistically significant difference compared to the healthy control group. Furthermore, no statistically significant difference was found between mean MPV values in asthma exacerbation and asymptomatic period. MPV had a mean of 7.8, 7.7, and $7.9 \mathrm{fl}$ in acute attack, attack free period, and healthy controls respectively. Nacaroglu et al. (2016) confirmed these findings. There was no significant difference between acute cases, stable cases, and controls regarding MPV. Besides, other authors did not find any statistical difference between patients with asthma exacerbations, stable asthmatic patients and healthy subjects in terms of 
MPV values (Dolap et al., 2018). Hafez et al. (2019) reported that MPV was significantly reduced in exacerbated cases compared to stable cases, and controls.

In the current study, using a cut of value of $9.3 \mathrm{fl}$, MPV had sensitivity and specificity of 82 and $74 \%$ in predicting asthma, with an accuracy of $78 \%$. MPV during the asthmatic attack was a significant predictor of acute asthma ( $\mathrm{p}=$ 0.036). In another study by Agapakis et al. (2016), the receiver operating characteristic curve showed that the best cut point of mean platelet volume (8.2 fL), which is suggested to discriminate between the acute exacerbation phase and the stabilization phase at the time of diagnosis.

In the current study, MPV did not have any significant correlation with any spirometric pulmonary function items, apart from VC \% predicted during the attack, which had a significant negative correlation.

Tuncel et al. (2012) stated that the presence of atopy, infection, eosinophilia, elevated IgE, severity of asthmatic exacerbation did not influence MPV values. Tural Kara et al. (2015) reported that during the attack, only the severe asthma attack group had a negative correlation between platelet count and FEV1. When all patients were examined after the attack, PDW was positively correlated with FEV1, FVC, FVC and FEF25-75.Considering all the patients, no correlation between MPV, PCT, pselecting values and age at diagnosis, smoking exposure, concomitant allergic rhinitis, or family history of asthma was evident.
Mean platelet volume was significantly correlated with C-reactive protein, WBC count, and neutrophil percentage in the exacerbation period. In contrast, no significant correlation between mean platelet volume and FEV1 was found. Also, there was no correlation between mean platelet volume and duration of hospitalization (Agapakis et al., 2016). Nacaroglu et al. (2016) stated that asthma, severity of asthma exacerbation, immunotherapy, infection, atopy, and esinophil count have no effect on MPV. Other authors demonstrated that, during exacerbation phase and stable phase, MPV was positively correlated with FEV1/FVC, FEV1\%, FVC\%, FEF25$75 \%$, whereas it was negatively correlated with hsCRP, PCT, symptoms duration, WBC, and platelet count. Moreover, they were negatively correlated with symptom duration during exacerbation phase and positively correlated with each other (Hafez et al. 2019).

\section{CONCLUSION}

The MPV was found to be lower during exacerbation phase compared to stable phase. The negative correlation between MPV and hs-CRP and WBC, and its positive correlation with FEV1 indicated that MPV may be a determinant of airway inflammation severity. Therefore, MPV may be used in determining the acute asthma exacerbation severity.

\section{REFERENCES}

1. Agapakis, D. I., Massa, E. V., Hantzis, I., Maraslis, S., Alexiou, E., Imprialos, K. P., ... \& Satsoglou, E. (2016): The role of mean platelet volume in chronic obstructive pulmonary disease exacerbation. Respiratory care, 61(1): 44-49. 
2. Obaidi, A. H. A. A., Samarai, A. G. M. A., Jawad, A. K. Y., \& Janabi, J. M. A. (2010): Association Between C Reactive Protein and Asthma. Turk Toraks Dergisi/Turkish Thoracic Journal, 11(3).

3. Dogru, M., Aktas, A., \& Ozturkmen, S. (2015): Mean platelet volume increased in children with asthma. Pediatric Allergy and Immunology, 26(8): 823-826.

4. Dolap, U, Tuğ, T, and Konuk, $\mathrm{S}$ (2018): Evaluation of Mean Thrombocyte Volumes in Asthma Patients During Acute Exacerbations and Stable Periods. Archives of Clinical and Biomedical Research, 2(1): 16.

5. Flad, H-D and Brandt, E. (2010): Plateletderived chemokines: pathophysiology and therapeutic aspects. Cellular and Molecular Life Sciences, 67(14): 2363-2386.

6. Hafez, MR, Eid, HA, Elsawy, SB, Eldin, NE and El Madbouly, AA. (2019): Assessment of bronchial asthma exacerbation: the utility of platelet indices. Egyptian Journal of Bronchology, 13(5): 623.

7. Nacaroglu, H. T., Isguder, R., Bahceci, S. E., Ceylan, G., Korkmaz, H. A., Karaman, S., ... \& Can, D. (2016): Can mean platelet volume be used as a biomarker for asthma? Advances in Dermatology and Allergology/Postępy Dermatologii i Alergologii, 33(3): 182.
8. Reddel, HK and Levy, ML. (2015): The GINA asthma strategy report: what's new for primary care? NPJ Prim Care Respir Med, 25(1): 1-4.

9. Sun, W-X, Zhang, J-R, Cao, Z-G, Li, Y and Wang, R-T. (2014): A decreased mean platelet volume is associated with stable and exacerbated asthma. Respiration, 88(1): 3137.

10. Tuncel, T, Uysal, P, Hocaoglu, AB, Erge, DO, Karaman, $O$ and Uzuner, N. (2012): Change of mean platelet volume values in asthmatic children as an inflammatory marker. Allergologia et immunopathologia, 40(2): 104-107.

11. Tural Kara, T, Yılmaz Özbek, Ö and Tahire Köksal, B. (2015): Evaluation of Platelet Activation During an Asthmatic Attack in Children. Turkish Journal of Pediatric Disease, 2: 84-89.

12. Ullmann, N., Mirra, V., Di Marco, A., Pavone, M., Porcaro, F., Negro, V., ... \& Cutrera, R. (2018): Asthma: differential diagnosis and comorbidities. Frontiers in pediatrics., 6: 276.

13. Yuri Gasparyan, A., Ayvazyan, L., $P$ Mikhailidis, D., \& D Kitas, G. (2011): Mean platelet volume: a link between thrombosis and inflammation? Current Pharmaceutical Design, 17(1): 47-58. 


\section{دور منوسط حجم الصفائح الدموية كمؤشر حيوي في التفاقم الحاد للاربو الثعبي الثموبي}

السعودي عوض محمد مصطفي، رفعت أبو الفتوح أبو السعد، إبراهيم حسن البنا

$$
\text { إبراهيم }
$$

قسم الأمراض الصدرية، كلية الطب، جامعة الأزهر، القاهرة

\section{E-mail: soudybadr2@yahoo.com}

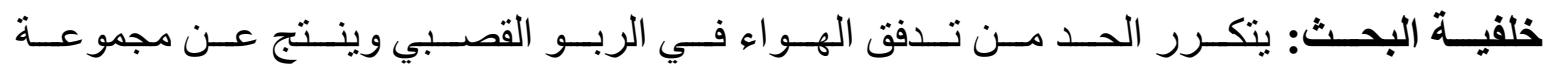

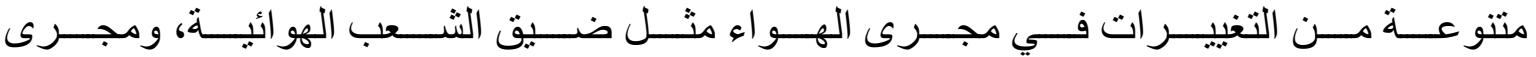

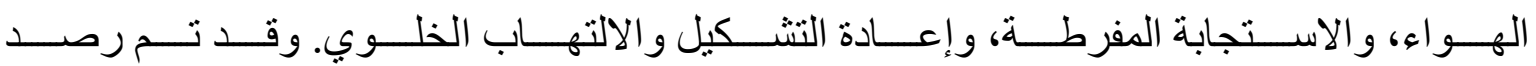

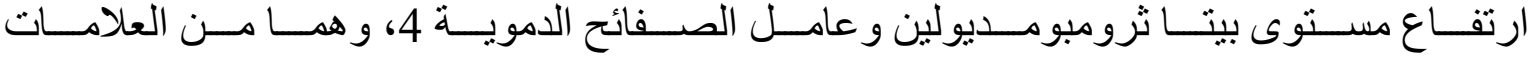

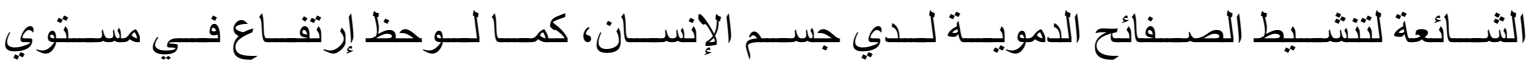

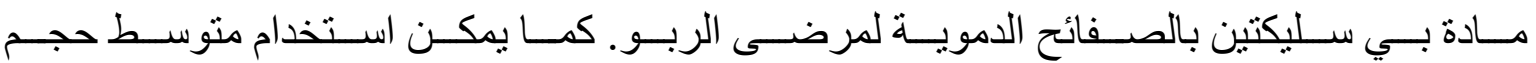
الصفائح الدموية كمؤشر على تنشيط الصفائح الدموية.

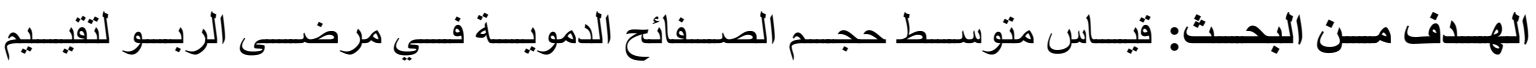
إستخدامه كمؤشر بيولوجي لتفاقم الربو.

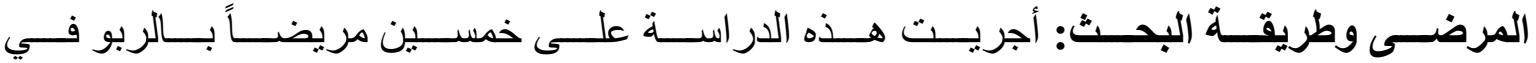

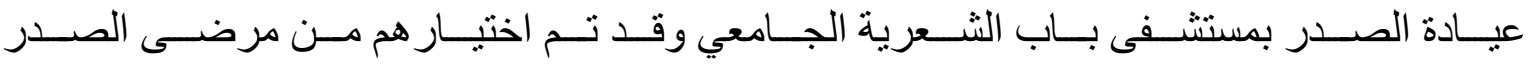

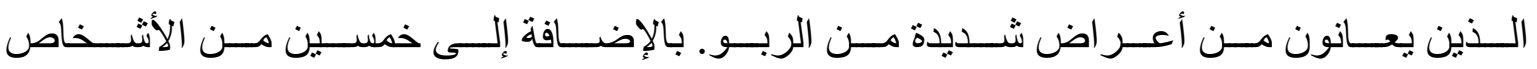
المنطابقين في السن و الجنس لمجمو عه الاختبار كمجمو عة ضابطة.

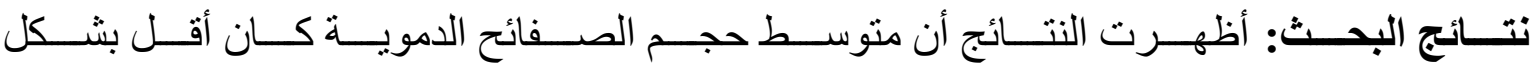

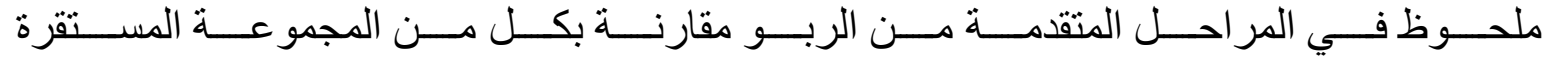

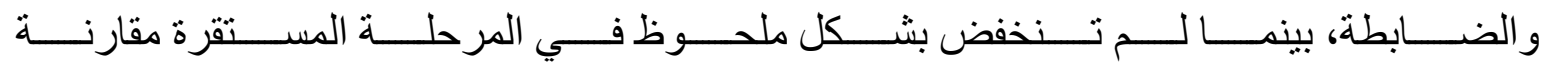

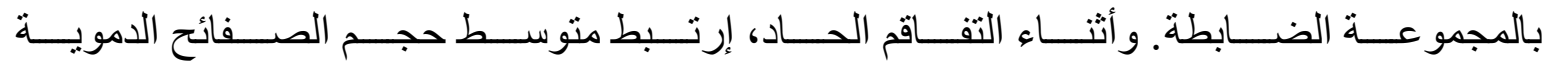

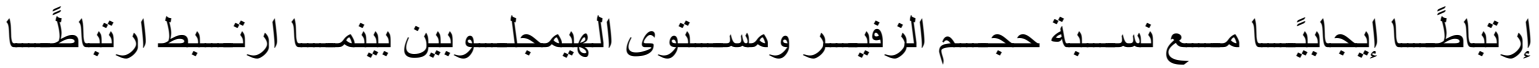

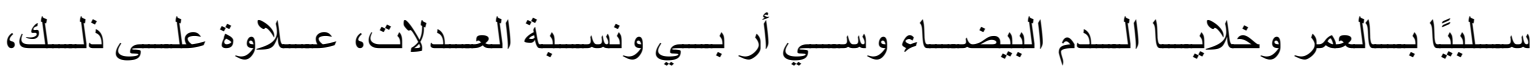

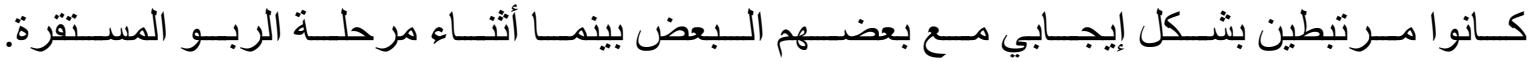




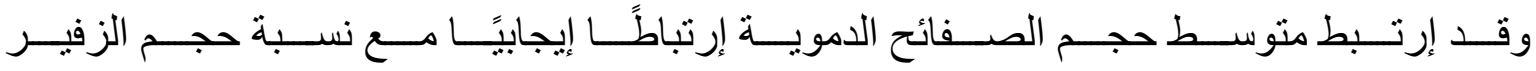

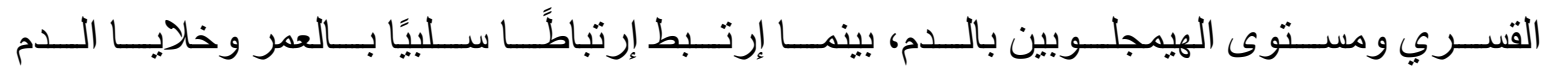

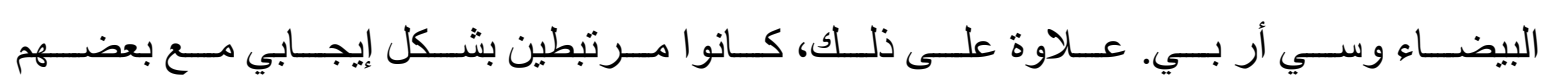
البعض.

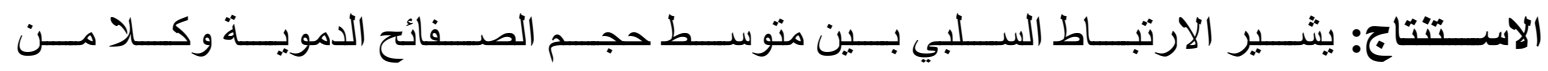

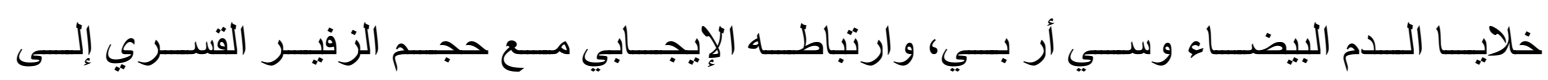

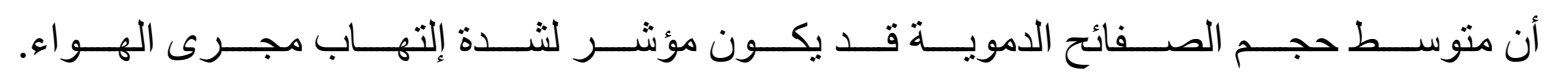
لذللك، يمكن استخدامه في تحديد شدة تفاقم الربو الحاد.

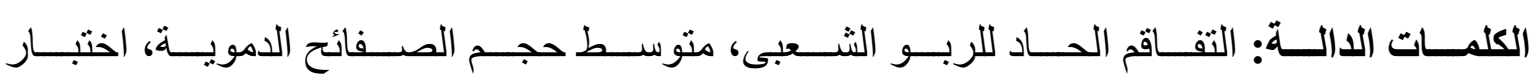
وظائف التنفس. 